\title{
O lugar do texto e do discurso em teorias enunciativas e discursivas
}

\author{
Sônia Virginia Martins Pereira*
}

\begin{abstract}
Resumo
O texto destina-se à reflexão sobre as noções de discurso e texto, no escopo de uma linguística da enunciação e do discurso. O estudo é de cunho teórico e tem por finalidade o entrelaçamento dessas noções nucleares que alicerçam teorias enunciativo-discursivas, em especial, a teoria dialógica, a partir da qual são relacionadas a texto e discurso outras noções, como enunciação, enunciado e gênero. No percurso do texto, as noções são definidas, alicerçadas em teóricos de referência dos campos enunciativos e discursivos, a partir do que se bifurcam e, posteriormente, convergem para os estudos dialógicos de onde podemos extrair uma teoria do conhecimento sobre a linguagem que tem por foco a interação social, na qual texto, discurso, enunciado e gênero são alguns de seus pilares. Diante da construção teórico-metodológica legada pelos estudos dialógicos, nos quais as noções são categorias analíticas, consideramos que a teoria dialógica dispõe de importantes dispositivos para a análise da atividade linguageira.
\end{abstract}

Palavras-chave: Noções teóricas. Teorias enunciativas. Teorias discursivas.

\section{The Role of Text and Speech in Enunciative and Discursive Theories}

\begin{abstract}
This work is developed towards a reflection on the notions of text and speech, on the scope of an enunciation and discourse linguistics. The study is theoretical and is meant to intertwine the core notions on which enunciative-discursive theories are based, in particular, the dialogical theory, used to relate other notions to those of text and discourse, such as enunciation, enunciate and genre. Throughout the text, the notions are defined, based on theorists of renown in the enunciative and discoursive fields, where they bifurcate and, eventually, converge to the dialogical studies from which we can extract a theory of knowledge about speech focused on the social interaction, with pillars consisting of text, discourse, enunciate and genre, among others. In face of the theoretical-methodological left by dialogical studies, in which the notions are analytical, we consider that the dialogical theory has important devices to the analysis of the linguistic activity.
\end{abstract}

Keywords: Theoretical notions. Enunciative theories. Discursive theories.

Recebido: $15 / 01 / 2018$

Aceito:15/05/2018

1 Universidade Federal Rural de Pernambuco (UFRPE). Doutora em Letras e Professora Adjunta da UFRPE. 


\section{Introdução}

Tomar as noções de discurso, texto, enunciado e gênero isoladamente, de modo que, se não a estabelecer uma separação rígida entre as terminologias, mas que deixasse nítidas suas particularidades seria um caminho possível para este estudo. Tal separação poderia mostrar que entre esses objetos teóricos distintos há uma hierarquia conceitual, na qual o discurso é visto como uma dimensão ampla da linguagem em uso, abarcada pela materialidade linguística que o texto representa, sendo este, portanto, a manifestação do discurso ${ }^{2}$. Os gêneros representariam o ponto convergente entre texto e discurso, conforme Sobral (2010) e o enunciado visto como elo dialógico em que são encadeadas as noções, no pensamento bakhtiniano, podendo ser tomado como o próprio discurso, o próprio texto ou o próprio gênero.

Entretanto, ao nos debruçarmos nos estudos de diferentes pesquisadores e teóricos do texto e do discurso (BAKHTIN, 1997 e 2000; VOLOCHÍNOV, 1997; FARACO, 2009; PONZIO, 2012; BRANDIST, 2012; MAINGUENEAU, 2010; FIORIN, 2006; SOBRAL, 2010; BARROS, 2005; BRAIT, 2012, 2010, 2006, 2005, 2003), percebemos que o encaminhamento pensado para fundamentar teoricamente a discussão, com a separação entre as concepções, não teria a produtividade esperada, uma vez que as noções teóricas mantêm relações entre si e são convocadas para um diálogo epistemológico, mesmo que as linhas de abordagem divirjam em alguns pontos.

Em consequência, traçamos novos caminhos para o percurso enunciativo da sustentação teórica deste estudo, a fim de refletir sobre texto, discurso, gênero e enunciado como objetos teóricos, de modo globalizante, no interior da análise dialógica do discurso, mas no diálogo necessário com outras perspectivas textuais, enunciativas e discursivas. Assim é que, no primeiro tópico, apresentamos objetos de teorias da enunciação e do discurso discutindo aspectos epistemológicos e terminológicos descrevendo, em linhas gerais, correntes teóricas que apresentaram embriões de elementos enunciativo-discursivos - ainda que dependentes do estruturalismo - até chegarmos ao subtópico que dedicamos aos estudos dialógicos. No segundo tópico, discutimos as noções com base em obras dos pensadores russos que fundamentam os estudos dialógicos. Nas considerações finais, retomamos, em linhas gerais, a discussão desenvolvida no texto, compreendendo a produtividade dos construtos teóricos da teoria dialógica como dispositivo de análise.

\section{0 texto, além da frase, sob o olhar de teorias enunciativo-discursivas}

Correntes linguísticas diversas apresentam perspectivas também diversas para um mesmo objeto de estudo, haja vista a relação com a língua e com a linguagem ser mediada pela concepção que se tem sobre elas. Desse modo, acreditamos na pertinência da reflexão sobre visões de diferentes correntes dos estudos da linguagem que conservam suas peculiaridades sobre um mesmo objeto teórico, no caso mais específico, texto e discurso, examinando postulados de teorias da enunciação, de teorias do texto e de vertentes de análises do discurso, com a centralização nos estudos bakhtinianos.

\footnotetext{
2 A expressão "materialidade linguística" foi escolhida para nomeação do que entendemos do texto como manifestação linguística do discurso, corroborando o que defendem Possenti (2012), para quem os textos “são lugares de materialização dos discursos" (p. 252); Brait (2012), que observa a articulação, conduzida por Volochínov (1997), entre materialidade semiótica e fenômeno ideológico para definir o objeto texto e, assim, a autora, em seu ensaio, apresentar sua própria definição desse objeto teórico como uma organização coerente, conjunto "em que a associação materialidade sígnicaideológica funciona como princípio organizador e revelador do domínio dos signos, da esfera ideológica, da produtividade na vida social [...]" (BRAIT, 2012, p. 13); e Sobral (2010), que entrelaça discurso, gênero e texto, vendo o discurso como "espaço da linguagem em uso [...] segundo o gênero no qual se insere e mediante a mobilização da materialidade textual." (SOBRAL, p. 10-11).
} 
Nesta discussão, que envolve o aparato teórico-metodológico de determinadas teorias, refletiremos sobre algumas noções e ideias que subsidiam as concepções de texto, discurso, gênero e enunciado e sua dependência de concepções de língua e de linguagem, com apoio nos fundamentos epistemológicos que apresentam as teorias. Entre essas noções, consideramos significativo iniciar a exposição por questões pertinentes à enunciação, visto que sugerem caminhos para entendermos como teorias enunciativas e discursivas são trabalhadas por diferentes teóricos em sua visão expandida sobre a linguística.

Estudos no campo da linguística posteriores aos desenvolvidos por Saussure (1995), que visavam situar a linguística como disciplina das ciências humanas, podem ser considerados como uma tentativa de preencher a lacuna deixada pelo teórico genebrino ao limitar o campo de estudos da linguística estabelecendo a cisão entre língua e fala, linguístico e extralinguístico. Os estudos desenvolvidos desde então, por diversos modos, se lançaram a preencher os espaços entre as dicotomias estáveis, resgatando do isolamento da fala outros elementos só possíveis por meio desta, os quais, sem dúvida, não podem ser desprezados por teóricos e estudiosos da linguagem humana.

Por conseguinte, os estudos posteriores ao Curso de linguística geral retomaram questões ignoradas pela linguística saussureana, expandiram seu campo de estudos, construíram as bases para outras investigações. Todavia, esses estudos não se afastaram muito do que propôs Saussure (idem), visto que apresentaram novas definições sobre os mesmos conceitos estruturalistas, reforçando a separação entre o que seria exame da ciência linguística e o que seria de outras ciências.

Algumas mudanças significativas ocorreram, em especial, quando teóricos da linguística se voltaram para questões sobre a enunciação na linguagem, sedimentando, de certa forma, o caminho para abordagens posteriores mais amplas, mas mantiveram, por meio de outras nomeações e definições, a distinção entre o escopo que estaria sob o domínio da linguística e de domínio de outros campos científicos ou disciplinas. No território da linguística, em geral, nesses estudos, o limite seriam as unidades frasais, isoladas de seu contexto de uso, o que, consequentemente, negou o todo do texto como unidade de sentido e, mais ainda, como objeto de estudo.

Como objeto de análise, o texto só mereceu atenção por parte de teorias do texto e teorias do discurso, como a semiótica, a linguística textual, a análise do discurso, entre outras, as quais têm expandido e reconfigurado seu arcabouço teórico-metodológico, com vistas a abarcar em seu aparato analítico, os diversificados elementos componentes desse objeto teórico. Entretanto, quanto às teorias da enunciação, precisamos ressalvar que estas nunca tiveram como finalidade investigativa a teorização específica sobre o texto, mas contribuíram com noções e elementos teórico-metodológicos que, ao serem transpostos, em certa medida, de seu enquadre teórico para determinados contextos, puderam subsidiar análises frutíferas sobre o texto. Como exemplificação de tendências a um movimento enunciativo inaugural, mas ainda firmado em conceitos saussureanos, tais como vistos por Flores e Teixeira (idem), temos as teorizações de Charles Bally, Roman Jakobson, Émile Benveniste, Osvald Ducrot, Jacqueline Authier-Revuz e outros.

Charles Bally é caracterizado por Flores e Teixeira (idem) como o primeiro pós-saussureano, pelo registro de seu interesse sobre os estudos de enunciação, no prefácio que assina com Alberto Sechehaye, no Curso de linguística geral, no qual atribuem à organização póstuma desta obra sua incompletude, numa tentativa de explicar a razão de disciplinas como a semântica mal tenham aflorado e a ausência de uma linguística da fala nos estudos de Saussure. No entendimento de Flores e Teixeira (idem), Bally desenvolve essa linguística da fala, quando elabora uma estilística da língua, em Traité de stylistique française, no qual sugeria que a estilística passasse de normativa à descritiva.

Sua definição de estilística é contrária àquela voltada para o estudo científico de obras literárias, pois entende que a disciplina deva se preocupar com a presença da enunciação no enunciado e não somente com o enunciado propriamente dito, buscando investigar nos processos linguísticos de 
expressão do usuário da língua, o caráter social da expressividade linguística. Portanto, corroborando com o que constatam Flores e Teixeira (idem), podemos afirmar que há uma teoria da enunciação em Bally, pois "integra ao estudo da língua o contexto linguístico, desenvolvendo temas [...] que viriam polarizar a atenção da linguística textual iniciada pela Escola de Praga.” (FLORES e TEIXEIRA, 2012, p. 18).

A contribuição de Jakobson e sua linguística da comunicação também é vista como importante para os estudos enunciativos, pela importância da sua definição dos shifters e das funções da linguagem. ${ }^{3}$

Jakobson pode ser considerado um dos primeiros linguistas a pensar sobre as questões de enunciação, porque sua teoria das funções da linguagem e seu trabalho sobre shifters são algumas das primeiras sistematizações que se têm em linguística sobre o lugar do sujeito na língua. (FLORES e TEIXEIRA, 2012, p. 22).

Podemos considerar a teoria das funções da linguagem um estudo enunciativo em sentido amplo, visto que está na base da teoria de Jakobson (1974), a teoria da comunicação, uma concepção de língua como código, o que a afasta das teorias da enunciação, em sentido restrito. Entretanto, é inegável que o pioneirismo de Jakobson está na sistematização de uma perspectiva de estudo que se volta para a atividade da fala, ainda que, em linhas gerais, possamos entender as funções da linguagem como representações linguísticas do sujeito falante. Todavia, com os estudos dos shifters há uma sistematização do trabalho enunciativo da linguagem, pois são os elementos do código que remetem à mensagem, conforme as relações que Jakobson (idem) estabelece entre código e mensagem, baseado na teoria da comunicação. O estatuto da enunciação, em sua teoria, é o da atividade pela qual se manifesta a presença codificada do locutor no interior do enunciado.

Benveniste (2005) é, possivelmente, o primeiro linguista a propor um modelo de análise da língua direcionado à enunciação, mesmo inserido no quadro estruturalista saussereano e no apogeu do estruturalismo nas ciências humanas. A par dessa realidade, entendemos a dificuldade do linguista para a inclusão dos estudos da enunciação e, com estes, o da subjetividade, como objeto da linguística, mantendo-se fiel ao pensamento estruturalista, mas provendo meios de tratar do "homem falando que encontramos no mundo, um homem falando com outro homem", pois a "linguagem ensina a própria definição do homem" (Benveniste, 2005, p. 285).

Isto é o que caracteriza a linguagem, pois não se pode estabelecer oposição entre ela e o homem, como afirmado no capítulo Da subjetividade na linguagem, de Problemas de linguística geral I. É nesse capítulo que Benveniste (idem) retoma a divisão do sistema pronominal em pessoa e não pessoa, visto que o sujeito, em sua teorização, nasce da interação dada pelo uso do sistema linguístico, da ordem da língua, que possibilita a transição de locutor a sujeito, pela apropriação da língua. $O$ estudo da (inter)subjetividade, portanto, em Benveniste (idem), associa reflexões sobre a estrutura do sistema pronominal pessoal e a enunciação, o que indica sua permanência no modelo teórico saussureano.

No capítulo O aparelho formal da enunciação, de Problemas de linguística geral II, há a oposição entre linguística das formas e linguística da enunciação, cabendo à primeira a descrição das regras organizadoras da sintaxe da língua, o que pressupõe um objeto estruturado, sobre o qual se deve descrever suas regras imanentes. A segunda contém a primeira e insere no seu objeto de estudo a enunciação. No trecho, a seguir, Benveniste (1989) apresenta noções importantes para o esclarecimento sobre enunciação, discurso e texto:

A enunciação é este colocar em funcionamento a língua por um ato individual de utilização. O discurso, dir-se-á, que é produzido cada vez que se fala, esta manifestação da enunciação, não é simplesmente a "fala"? - É preciso ter cuidado com a condição específica da enunciação: é o ato mesmo de produzir um enunciado, e não o texto do enunciado, que é

3 Embrayeurs, em francês e embreantes, embreadores, dêiticos, entre outros, em português. 
nosso objeto. Este ato é o fato do locutor que mobiliza a língua por sua conta. A relação do locutor com a língua determina os caracteres linguísticos da enunciação. Deve-se considerála como o fato do locutor, que toma a língua por instrumento, e nos caracteres linguísticos que marcam esta relação. (BENVENISTE, 1989, p. 82).

Nas afirmações de Benveniste (1989), há a nítida separação entre o objeto de estudo da linguística da enunciação, o ato, do produto, o discurso. Embora não se detenha em desenvolver uma noção conceitual sobre o texto, em seus estudos sobre a enunciação, na passagem transcrita Benveniste (idem) sinaliza para o lugar desse objeto teórico como configuração linguística, distinguindo-o do discurso e do ato enunciativo.

A afirmação do linguista é de que do ato de enunciação nasce um enunciado, o discurso. Por essa linha de pensamento, o texto produzido no ato seria semelhante ao discurso, produto da enunciação. Portanto, ao texto devem ser estendidas as considerações dadas à frase nos estudos benvenisteanos, pois ambos são produtos da enunciação. "Ora, a expressão semântica por excelência é a frase." (BENVENISTE, 1989, p.229).

O objeto de estudo da língua, para Benveniste (idem), como visto, é o processo de enunciar, uma vez que o enunciado oferece os elementos de análise da enunciação e na relação estabelecida pelo locutor com a língua há a determinação das marcas linguísticas dessa enunciação. Tais marcas são observáveis no texto e pavimentam o caminho para a análise dos processos enunciativos, visto que o que se encontra textualmente explícito no enunciado pode servir como dispositivo para abarcar o processo de enunciação e revelar os meios pelos quais os sentidos são produzidos pelo locutor, os mecanismos que permitem ao homem inscrever-se e marcar-se na língua.

Outros teóricos podem ser arrolados como fundadores dos estudos enunciativos, com teorias e objetos de estudo próprios, mas ainda dependentes de uma linguística estruturalista, comprovando que o fenômeno linguístico, seja em seu nível fonológico, morfológico, sintático ou semântico pode ser estudado sob orientação enunciativa, a exemplo de Ducrot (1987), Authier-Revuz (1998), KerbratOrecchioni (1980), Culioli (1990), Fuchs (1994) e outros que mostram ser próprio da linguística da enunciação $0^{4}$ um objeto multifacetado, submisso às especificidades teórico-metodológicas impostas por diferentes teorias enunciativas.

Em Ducrot (1987) temos o estudo dos conectores, operadores, modalizadores etc.; AuthierRevuz (1998) nos apresenta suas investigações sobre incisas, glosas, pseudoanáforas etc.; KerbratOrecchioni (1980) dispõe o estudo de substantivos, verbos, adjetivos, implícitos e indica outros elementos de subjetividade, além da estrutura linguística; Culioli (1990) investe no estudo sobre negação, representação metalinguística em sintaxe, quantificação; Fuchs (1994) dedica-se ao estudo da paráfrase. Os objetos de estudo desses teóricos dependem dos objetivos visados, da ótica sobre o fenômeno investigado, entre outros aspectos. Entretanto, apesar desses diferentes objetos indicarem certa dispersão entre si, eles estão interrelacionados e são atraídos pela concepção de língua como ordem própria, atualizada pelo indivíduo a cada enunciação.

\footnotetext{
4 Os sintagmas "linguística da enunciação" e "teorias da enunciação" estão empregados conforme os estudos de Flores e Teixeira (2012) e Flores et al (2009), os quais apontam para um campo dos estudos enunciativos, que pode ser chamado de linguística da enunciação, sendo tal campo constituído por perspectivas diversificadas de estudo da enunciação, as teorias da enunciação. Nas palavras de Flores e Teixeira (2012): “(...) insistimos ainda na pertinência de se pensar em um campo - que denominamos de linguística da enunciação - dentro do qual coexistem teorias da enunciação. Afinal, é sempre de enunciação que se está a falar: enunciação e subjetividade; enunciação e argumentação; enunciação e polifonia; enunciação e metalinguagem; enunciação e comunicação etc". (p. 102). Nessa concepção, a linguística da enunciação deve ser vista como um ponto de convergência de diferentes teorias. É “(...) a nomeação do múltiplo, não do unívoco.”(p. 109).
} 


\section{A enunciação como atividade dialógica}

Pensar em estudos enunciativos é também considerar os estudos dos pensadores russos, de perspectiva dialógica, a "personalidade coletiva", o "coletivo pensante"s composto por teóricos que desenvolveram uma teoria da linguagem que antecipa reflexões, as quais, posteriormente, foram problematizadas e discutidas por Benveniste $(2005,1989)$, embora este teórico francês tenha permanecido fiel ao estruturalismo saussureano. Nos trabalhos dos teóricos russos, a intersubjetividade tem seu lugar garantido na concepção de linguagem formulada, caracterizando a enunciação como atividade eminentemente dialógica, em que a constituição do eu só é possível no encontro existencial com o outro. Diante disso, os pensadores veem o repetível e o irrepetível em articulação no processo de constituição do sentido. As noções de repetível e irrepetível recebem diferentes nomeações no conjunto da obra de Volochínov (1997) e de Bakhtin (1997; 2000), representantes do coletivo pensante:

\section{QUADRO 1 - Noções de repetível/irrepetível na obra bakhtiniana}

\begin{tabular}{|l|l|l|}
\hline \multicolumn{1}{|c|}{ Repetível } & \multicolumn{1}{c|}{ Irrepetível } & \multicolumn{1}{c|}{ Obra } \\
\hline significação & tema & Marxismo e filosofia da linguagem \\
\hline oração & enunciado & $\begin{array}{l}\text { Marxismo e filosofia da linguagem } \\
\text { Estética da criação verbal }\end{array}$ \\
\hline relações lógicas & relações diálogicas & $\begin{array}{l}\text { Marxismo e filosofia da linguagem } \\
\text { Problemas de poética de Dostoievski } \\
\text { Estética da criação verbal }\end{array}$ \\
\hline
\end{tabular}

Fonte: Elaborado pela autora

Como já bem posto por pesquisadores brasileiros do pensamento bakhtiniano (BRAIT, 2012, 2010, 2005; FARACO, 2009), as noções teóricas do grupo de pensadores russos devem ser compreendidas a partir do conjunto da obra, situando categorias, conceitos e noções no interior do contexto epistemológico e cultural que os originou. Como defende Brait (2010), essa postura investigativa contribui para distinguir "a perspectiva bakhtiniana de outras importantes teorias sobre a linguagem e, especialmente, estabelecer fronteiras bem nítidas entre designações idênticas para conceitos completamente diferentes, quando não contraditórios." (BRAIT, 2010, p. 15 e 16).

E, como procede Faraco (2009), em sua investigação sobre a filosofia da linguagem bakhtiniana, centrando-se nas ideias linguísticas dessa linha teórica, para "delinear as grandes coordenadas dessas ideias e situá-las no eixo da história” (FARACO, 2009, p. 9 e 10). Ou, ainda, como pensa Faria e Silva (2013), para quem "ser bakhtiniano é saber que, para cada conceito teórico, há uma verdadeira caça ao tesouro pelas diversas obras do Círculo" , pois a "construção dos conceitos se dá em toda a obra, não apenas em um ensaio." (FARIA E SILVA, 2013, p. 61).

Considerar os estudos enunciativos à luz das coordenadas teóricas bakhtinianas é reconhecer um pensamento de vanguarda, visto que os estudos dialógicos constituem de forma preliminar uma teoria que destaca o processo não reiterável da enunciação, o qual pressupõe diferentes enunciações. É considerar a importância da formulação das definições de enunciado, enunciado concreto e enunciação ${ }^{7}$

5 Com as expressões “personalidade coletiva” e "coletivo pensante” (MEDVIEDEV, Iúri Pávlovitch; MEDVIEDEV, Dária Aleksándrovna, 2014, p. 30, 41 e 43) e, com outras equivalentes, estamos renunciando à expressão Círculo de Bakhtin.

6 Como essa é uma transcrição literal do texto da autora, logo, a nomeação Círculo está sendo empregada por ela.

$7 \mathrm{Na}$ tradução do ensaio Os gêneros do discurso, diretamente da língua russa para a língua portuguesa, Bezerra (2016) afirma, em nota do tradutor, que, no referido ensaio "Bakhtin emprega o termo viskázivanie, derivado do infinitivo viskázivat, que significa ato de enunciar, de exprimir, transmitir pensamentos, sentimentos, etc. em palavras” (p. 11). 
no conjunto das obras dos teóricos russos, reconhecendo sua importância, como ressalta Brait (2005), "nas reflexões sobre a linguagem e, especialmente, suas consequências para os estudos enunciativos e discursivos contemporâneos." (BRAIT, 2005, p. 62).

A tecelagem da teoria da enunciação bakhtiniana é iniciada no capítulo 4 de Marxismo e filosofia da linguagem, "Das orientações do pensamento filosófico-linguístico", quando Volochínov (1997) opõese radicalmente às duas principais orientações do pensamento filosófico-linguístico, o subjetivismo idealista e o objetivismo abstrato e, a partir do quinto capítulo da mesma obra, passa a descrever o que, na sua visão, deveria ser objeto de estudo da linguística. É quando estabelece a noção de enunciação em sua condição de processo histórico não reiterável, no qual as formas linguísticas estão a serviço do evento de fala e este envolve bem mais do que está no sistema linguístico, pois no evento estão envolvidos as condições de produção, os interlocutores da interação verbal e o caráter social da atividade linguageira. A língua é vista como atividade em constante evolução, sendo atualizada à medida que é acionada em situações reais de fala; portanto, bem distante de ser vista como um sistema imutável ou como resultado de atos individuais.

Na realidade, o locutor serve-se da língua para suas necessidades enunciativas concretas (para o locutor, a construção da língua está orientada no sentido da enunciação da fala). Trata-se, para ele, de utilizar as formas normativas (admitamos, por enquanto, a legitimidade destas) num dado contexto concreto. (VOLOCHÍNOV, 1997, p. 92).

Junte-se a isso o fato de que para Volochínov (idem) o que fomenta o tom dialógico próprio do enunciado é que este só se constitui na relação gerada entre os interlocutores, na situação de produção enunciativa, o que, para o teórico, é decorrente do fato de a palavra dirigir-se a um interlocutor, pois "ela é função da pessoa desse interlocutor: variará se se tratar de uma pessoa do mesmo grupo social ou não, se esta for inferior ou superior na hierarquia social, se estiver ligada ao locutor por laços sociais mais ou menos estreitos [...]" (VOLOCHÍNOV, 1997, p. 112).

$\mathrm{Na}$ teoria dialógica, nega-se o caráter monológico ou individual da palavra, pois esta implica posicionamento dos interlocutores, um em relação ao outro, sob uma orientação social, sendo isto possível, apenas, pela interação entre esses interlocutores. Nessa visão, todo ato de fala é interacional e, ainda que assuma um forma monológica, há subtendida uma interlocução, na qual a projetação do outro se constitui como fator determinante.

Ressaltamos que as críticas estabelecidas por Volochínov (idem) revelam preocupação teórica quanto à função da exterioridade do enunciado em relação aos sentidos produzidos. Daí a importância de se considerar a situação de produção como o auditório social composto na enunciação e os interlocutores como indivíduos ativos da manifestação linguística. Desse modo, a crítica volochinoviana ao objetivismo abstrato está no isolamento que essa tendência estabelece entre a língua e seu exterior social, aquilo que lhe é constitutivo, lugar onde a língua é viva e vivida.

Tecidas as reflexões preliminares a respeito do que entendemos firmar-se no território constituído por teorias voltadas para a enunciação, para o texto e para o discurso, de base bakhtiniana, no próximo tópico passaremos a explorar formulações teóricas que convergem para noções de texto, discurso, enunciado e gênero especificamente empreendidas pelos estudos dialógicos.

Ressalta, porém, que em Marxismo e filosofia da linguagem, obra, para o tradutor, "até hoje sem autoria definida" (BEZERRA, 2016, p. 11), - mas que neste estudo atribuímos a autoria a Volochínov (1997), com base em Tylkovski (2010) -, o termo consta, em traduções para o português, como "enunciado" e "enunciação". Entretanto, o tradutor assegura que Bakhtin não faz distinção entre "enunciação" e "enunciado", ao empregar o termo viskázivanie tanto para o ato de produção de discurso oral quanto para o do discurso escrito. 


\subsection{A abordagem dialógica da problemática do texto e do discurso}

Parece inevitável que nas discussões acerca das concepções de texto, discurso, enunciado e gêneros, à luz do pensamento dialógico, adentremos, prioritariamente, pelo viés da língua. Numa postura de negação da concepção de língua como sistema de categorias gramaticais, Volochínov (1997) defende que

a verdadeira substância da língua não é constituída por um sistema abstrato de formas linguísticas nem pela enunciação monológica isolada, nem pelo ato psicofisiológico de sua produção, mas pelo fenômeno social da interação verbal, realizada através da enunciação ou das enunciações. (VOLOCHÍNOV, 1997, p. 123).

Ao constituir sua abordagem teórica por meio da perspectiva de língua como fenômeno produzido na interação verbal, Bakhtin (1997) pavimenta um caminho para se estudar a língua em sua integridade concreta e viva, só possível por meio do discurso. O teórico sugere esse caminho analisando o discurso em Dostoiévski, objeto de estudo a partir do qual alguns princípios da atividade discursiva são trabalhados, tais como, o discurso alheio, a bivocalidade, transmissão do discurso do outro, entoação, entre outros.

As palavras do outro, introduzidas na nossa fala, são revestidas inevitavelmente de algo novo, da nossa compreensão e da vossa avaliação, isto é, tornam-se bivocais. O único que pode diferençar-se é a relação de reciprocidade entre essas duas vozes. A transmissão da afirmação do outro em forma de pergunta já leva a um atrito entre duas interpretações numa só palavra, tendo em vista que não apenas perguntamos como problematizamos a afirmação do outro. O nosso discurso da vida prática está cheio de palavras de outros. Com algumas delas fundimos inteiramente a nossa voz, esquecendo-nos de quem são; com outras, reforçamos as nossas próprias palavras, aceitando aquelas como autorizadas para nós; por último, revestimos terceiras das nossas próprias intenções, que são estranhas e hostis a elas. (BAKHTIN, 1997, p. 195).

É possível relacionar a citação de Bakhtin (idem), com o que defende Volochínov (1997), ao interrelacionar fala, condições de comunicação e estruturas sociais, as quais, em sua visão, estão indissoluvelmente ligadas. Volochínov (idem), em sua crítica à teoria da expressão, postula que o conteúdo a ser expresso e sua objetivação externa resultam da expressão semiótica, inexistindo, assim, atividade mental sem expressão semiótica; admite, portanto, que a atividade mental tem seu centro organizador fora do indivíduo, na própria interação verbal. A isto acrescenta que a atividade mental é organizada pela expressão e não o contrário. A expressão modela e determina a orientação da atividade mental possibilitando que o mundo interior do indivíduo se adapte às possibilidades de sua expressão e às suas possíveis orientações.

Desse modo, tanto a atividade mental do indivíduo como sua expressão exterior são constituídas no território social; inclusive o percurso que leva à atividade mental, o conteúdo a exprimir, à sua objetivação externa, a enunciação, estão situados nesse território. Significa que no pensamento dialógico, qualquer enunciação, até a expressão verbal de uma necessidade, é socialmente construída, o que nos leva a ponderar sobre a palavra como força ideológica, a palavra como material privilegiado da comunicação cotidiana. ${ }^{8}$

A interação verbal produz os enunciados que exprimem e realimentam a ideologia do cotidiano, expressão utilizada por Volochínov (idem) para conceituar o domínio da palavra exterior e o interior e

8 O vocábulo está sendo empregado em sua dupla acepção, na língua russa, com fundamento no estudo de Stella (2005). Diz o autor que, numa primeira acepção, mantém correspondência direta com seu significado em português e, numa segunda acepção, a equivalência é com o termo "discurso". 
que não compõe, ainda, um sistema. Essa ideologia do cotidiano é expressa por atos, palavras e gestos e permite que os sistemas ideológicos já constituídos - ciência, arte, moral, religião - cristalizemse a partir dela, o que nos indica que os sistemas ideológicos fixados e a ideologia do cotidiano influenciam-se mutuamente, permitindo sua (re)construção constante. Vemos, desse modo, que a concepção de linguagem construída na teoria dialógica lança novo olhar e nova compreensão sobre o papel da interação verbal na formação das ideologias e na construção da subjetividade do indivíduo.

É no fluxo das trocas verbais que a palavra se constitui como signo ideológico, transformando-se e produzindo significados, conforme o contexto enunciativo em que surge. A ligação entre a linguagem e a vida dá-se pelo diálogo, o qual é produzido pela interação social. Ao situar o diálogo na gama de textos e discursos que compõe a estrutura simbólica e ideológica de uma cultura, Volochínov (idem) atenta para o contexto ideológico e os diferentes modos pelos quais este influencia a consciência individual e a consciência individual o contexto ideológico.

$\mathrm{O}$ emprego da noção de palavra/discurso na teoria dialógica está intimamente relacionado às discussões inerentes à língua, fala, linguagem e enunciação, visto que há ligações que não se rompem entre tais noções, pela amplitude da concepção de discurso empreendida pelo coletivo pensante, em especial, porque houve um deslocamento do estudo da palavra, nos estudos bakhtinianos, como assevera Stella (2005), ao ser retirada da abstração, extirpada de sua realidade social, estudada como imanência de significado, para adquirir estatuto de signo ideológico.

Concepções tradicionais sobre a palavra como objeto de estudo, são vistas sob os enfoques da gramática greco-latina, em sua partição e organização das partes das palavras em paradigmas de flexão e declinação; da filologia, em seu trabalho de descrição da evolução histórico-fonética da palavra; e da linguística, em suas fases de observação da palavra, a da organização das línguas em suas famílias e ramificações e a da descrição das relações estruturais em níveis diferenciados, a partir da palavra. Para esta descrição, a semântica estava constituída como um dos níveis da descrição estrutural da linguística e o sentido da palavra estudado pela semasiologia e pela onomasiologia. Desses estudos tradicionais, localizados em fins do século XIX e início do século XX, para os estudos bakhtinianos, inseridos nas primeiras décadas do século XX, a palavra, como objeto teórico, passou a ser concebida sob nova visada, a partir do ponto de vista da linguagem em uso, no que sua historicidade passou a ser considerada.

Nas seguintes obras do coletivo pensante, a concepção de palavra-discurso é assim exposta:

a. Em Discurso na vida e discurso na arte ${ }^{9}$, publicado em 1926, com assinatura dupla de Volochínov e Bakhtin é onde, pela primeira vez, aparece um novo enfoque para o estudo da palavra, quando os teóricos russos assinalam seu objetivo de compreender o enunciado poético, a partir dos enunciados cotidianos:

O propósito do presente estudo é tentar alcançar um entendimento do enunciado poético, como uma forma desta comunicação estética especial, verbalmente implementada. Mas para fazer isso nós precisamos antes analisar em detalhes certos aspectos dos enunciados verbais fora do campo da arte - enunciados da fala da vida e das ações cotidianas, porque em tal fala já estão embutidas as bases, as potencialidades da forma artística. Além disso, a essência social do discurso verbal aparece aqui num relevo mais preciso e a conexão entre um enunciado e o meio social circundante presta-se mais facilmente à análise. (VOLOSHINOV/BAKHTIN, 1976, p. 6).

Na parte em que se dedicam a elucidar aspectos do discurso verbal na vida cotidiana, os teóricos russos ponderam sobre a não autossuficiência dele, pois é resultado de uma situação pragmática

9 Obra assinada originalmente por Volochínov, está sendo referenciada, neste estudo, na coautoria Voloshinov/Bakhtin, pela tradução de Faraco e Tezza, de 1976. Em tradução mais recente dos artigos de Volochinov (2013), A construção da enunciação e outros ensaios, não consta Bakhtin como coautor desse artigo. 
extraverbal, o que lhe determina uma relação muito próxima com a situação em que foi gerado. Assim, entendem que as avaliações dos enunciados concretos realizadas sob qualquer critério - ético, cognitivo, político etc., abrangem fatores verbais e situação extraverbal, sendo necessário analisar como é estabelecida a relação entre elementos verbais e extraverbais, entre o dito e o não-dito. Para isso advogam que, ainda que seja feita uma análise exaustiva da parte verbal do enunciado, com a definição de seus segmentos fonéticos, morfológicos e semânticos, não se pode ter o sentido global dele, pois faltaria o contexto extraverbal para a produção de seus sentidos.

$\mathrm{Na}$ visão dos teóricos, o contexto extraverbal do enunciado engloba três fatores, que, na nossa visão, podem servir como dispositivo de análise dos enunciados concretos: o horizonte espacial e ideacional comum dos interlocutores, o conhecimento e a compreensão comum da situação por parte dos interlocutores e sua avaliação comum dessa situação.

Chamamos a atenção para o termo "comum" nos três fatores, pois nos parece que, com esse termo, é estabelecido um princípio geral para a análise do enunciado, o que é confirmado quando Voloshinov ${ }^{10}$ Bakhtin (1976) asseveram que o "conjuntamente visto", o "conjuntamente sabido" e o "unanimemente avaliado" estão implicados e dão sustentação ao enunciado, que se torna dependente deles.

[...] o enunciado concreto, sempre une os participantes da situação comum como coparticipantes que conhecem, entendem e avaliam a situação de maneira igual. $\mathrm{O}$ enunciado, conseqüentemente, depende de seu complemento real, material, para um e o mesmo segmento da existência e dá a este material expressão ideológica e posterior desenvolvimento ideológico comuns. (VOLOSHINOV/BAKHTIN, 1976, p. 6).

A situação extraverbal se integra ao enunciado tornando-se parte constitutiva de sua significação e, consequentemente, as duas partes constitutivas do enunciado concreto, como um todo significativo, são a parte percebida ou realizada em palavras e a parte presumida.

Embora, aparentemente, a situação leve a pensar algo na mente do falante, um ato físico-subjetivo - pensamento, ideia, sentimento -, o social e o objetivo são a base do individual e do subjetivo. Os julgamentos de valor presumidos são atos sociais regulares e fundamentais e não emoções individuais, mesmo que estas possam surgir como "sobretons acompanhando o tom básico da avaliação social", visto que o "eu pode realizar-se verbalmente apenas sobre a base do nós." (VOLOSHINOV/ BAKHTIN, 1976, p. 8).

Como reforço a tal ideia, os teóricos comparam o enunciado a um entimema, mas social, pois o presumido é conhecido pelos que pertencem a um mesmo campo social. Assim, o enunciado concreto estabelece conexões com a vida e não pode estar separado dela, sob pena de perder a significação. Mas o contexto imediato pode ter um escopo amplo ou reduzido e o horizonte comum do qual depende o enunciado pode se expandir no espaço e no tempo. Nisso, o presumido pode pertencer à família, ao clã, à nação, à classe podendo compreender dias, anos ou épocas inteiras.

Ao refletirem sobre a importância da avaliação presumida, Voloshinov e Bakhtin (1976) reafirmam que um julgamento de valor existe plenamente, sem estar incorporado ao discurso e sem derivar deste; ao contrário, é a avaliação valorativa que determina a seleção do material verbal e a forma do todo verbal. É na entoação que o julgamento de valor encontra sua expressão, pois esta estabelece um elo entre o discurso verbal e o contexto extraverbal, transportando o discurso verbal para além do verbal. Dando continuidade às suas observações sobre a natureza social da entoação, os teóricos afirmam que

A entoação só pode ser compreendida profundamente quando estamos em contato com os julgamentos de valor presumidos por um dado grupo social, qualquer que seja a extensão deste grupo. A entoação sempre está na fronteira do verbal com o não-verbal, do dito com o

10 Grafia como consta na tradução de Faraco e Tezza. 
não-dito. Na entoação, o discurso entra diretamente em contato com a vida. E é na entoação sobretudo que o falante entra em contato com o interlocutor ou interlocutores - a entoação é social por excelência. Ela é especialmente sensível a todas as vibrações da atmosfera social que envolve o falante. (VOLOSHINOV/BAKHTIN, 1976, p. 10).

Na concepção dos teóricos, cada instância da entoação é orientada em duas direções: a relacionada ao interlocutor como aliado ou testemunha, e a relacionada ao objeto do enunciado como um terceiro participante. É a orientação social dupla que determina todos os aspectos da entoação e a torna inteligível. E os teóricos ainda argumentam que toda expressão é produto da interação social de três participantes: o falante (autor), o interlocutor (leitor) e o tópico (o "que" ou o "quem") da fala (o herói), pois entendem que "o discurso verbal é um evento social: ele não está autoencerrado no sentido de alguma quantidade linguística abstrata, nem pode ser derivado psicologicamente da consciência subjetiva do falante tomada em isolamento." (VOLOSHINOV/BAKHTIN, 1976, p. 13).

b. Em Marxismo e filosofia da linguagem, Volochínov (1997), encerra o primeiro capítulo desta obra, intitulado Estudo das ideologias e filosofia da linguagem, especificando as propriedades da palavra, que foram examinadas no capítulo, quais sejam: pureza semiótica, neutralidade ideológica, possibilidade de interiorização, fenômeno de todo ato consciente. Tais propriedades fazem da palavra o objeto fundamental do estudo das ideologias, o que, na ótica do teórico, indica que "as leis da refração ideológica da existência em signos e em consciência, suas formas e seus mecanismos, devem ser estudados, antes de mais nada, a partir desse material que é a palavra" (VOLOCHÍNOV, 1997, p. 38).

É sob tais bases que Volochínov (idem) descreve as propriedades definidoras da palavra e, a partir delas, entendemos que a pureza semiótica diz respeito à capacidade de funcionamento e circulação da palavra como signo ideológico, nas mais diferentes esferas de atividade, o que a diferencia de materiais produzidos para funcionar em uma determinada esfera.

Mas esse aspecto semiótico e esse papel contínuo da comunicação social como fator condicionante não aparecem em nenhum lugar de maneira mais clara e completa do que na linguagem. A palavra é o fenômeno ideológico por excelência. A realidade toda da palavra é absorvida por sua função de signo. A palavra não comporta nada que não esteja ligado a essa função, nada que não tenha sido gerado por ela. A palavra é o modo mais puro e sensível de relação social. (VOLOCHÍNOV, 1997, p. 36).

A neutralidade ideológica estaria no fato de que a palavra não teria uma função ideológica dada a priori, mas assumiria qualquer uma, em qualquer campo.

Mas a palavra não é somente o signo mais puro, mais indicativo; é também um signo neutro. Cada um dos demais sistemas de signos é específico de algum campo particular da criação ideológica. Cada domínio possui seu próprio material ideológico e formula signos e símbolos que lhe são específicos e que não são aplicáveis a outros domínios. $\mathrm{O}$ signo, então, é criado por uma função ideológica precisa e permanece inseparável dela. A palavra, ao contrário, é neutra em relação a qualquer função ideológica específica. Pode preencher qualquer espécie de função ideológica: estética, científica, moral, religiosa. (VOLOCHÍNOV, 1997, p. 36 e 37).

Pode causar estranhamento a afirmação de que a palavra seja um signo neutro, por revelar uma aparente contradição, se no pensamento dialógico ela é vista como produto ideológico, marcada por valores de um tempo-espaço, enfim, signo ideológico de uma posição social e histórica. Stella (2005) apresenta seu ponto de vista sobre esta questão baseado em aspectos estruturais da língua russa que aponta para uma provável ambiguidade do texto de Marxismo e filosofia da linguagem, proveniente de sua tradução para a língua portuguesa. 
Conforme o referido autor, o gênero gramatical do vocábulo "palavra", em russo, é neutro; sendo, portanto, nesse enquadre, a "palavra" neutra, no que o autor acrescenta que "o termo 'neutro' consultado em um dicionário de língua russa possui, dentre as acepções mais comumente utilizadas, o significado de 'meio', 'ambiente, ‘médio', ‘comum', funcionando também como o advérbio de lugar 'no meio de"' (STELLA, 2005, p. 179-180).

É o deslocamento promovido por Volochínov (1997) da palavra como entidade abstrata, gramaticalmente neutra, para a palavra como entidade de uso concreto, na interação entre falante e interlocutor, palavra-meio. É quando o teórico explica que é por meio da palavra que o "eu" define-se em relação ao "outro" e à coletividade, ao se valer das metáforas da "arena" e da "ponte" (VOLOCHÍNOV, 1997, p. 66, 113).

Em relação ao fenômeno de todo ato consciente, é destacada nesta propriedade a possibilidade de a palavra funcionar tanto na consciência do sujeito, no processo interno, por meio de sua compreensão e interpretação do mundo, assim como nos processos externos desenvolvidos nos espaços ideológicos onde a palavra circula. Deve ser ressaltado, entretanto, que não há uma identidade perfeita entre tais momentos de circulação, visto que o signo interno, presente na consciência individual do indivíduo, resultado da interação das vivências ideológicas desse indivíduo e o mundo exterior, distingue-se do signo original. Como também o signo externo que circula nos mais diversos espaços ideológicos não é semelhante ao que circula internamente na consciência de uma pessoa.

c. Na obra Estética da criação verbal, a palavra/discurso é difundida pelos gêneros do discurso, no querer-dizer, no intuito discursivo do indivíduo, que é aquilo que deve ser dito tendo-se em consideração interlocutores e contextos de circulação próprios.

O querer-dizer do locutor se realiza acima de tudo na escolha de um gênero do discurso. Essa escolha é determinada em função da especificidade de uma dada esfera da comunicação verbal, das necessidades de uma temática (do objeto do sentido), do conjunto constituído dos parceiros, etc. Depois disso, o intuito discursivo do locutor, sem que este renuncie à sua individualidade e à sua subjetividade, adapta-se e ajusta-se ao gênero escolhido, compõe-se e desenvolve-se na forma do gênero determinado. (BAKHTIN, 2000, p. 301).

Sem dúvida que a seleção de palavras, de formas linguísticas para a construção do projeto de dizer, são marcadas por traços que condicionam sua utilização a determinado gênero, em situação específica. Esse fato mostra que a escolha de determinadas palavras para determinada situação só é possível porque sua escolha já foi igualmente feita por diversos locutores em diversas outras situações semelhantes. Isto confirma a dinamicidade inerente ao gênero, pois supre as necessidades funcionais momentâneas de uso da palavra, como também pontua sua historicidade, que se desenvolve e se ajusta às novas condições de uso.

Aqui alcançamos o ponto de encontro de noções representativas do entrelaçamento textodiscurso-enunciado-gênero. Na visão bakhtiniana, a textualidade é definida na enunciação por meio dos gêneros que constituem os enunciados, em razão de o enunciado se originar dos elementos dos gêneros, formas relativamente estáveis de usos das manifestações virtuais da língua. Portanto, a noção de texto esboçada nos estudos dialógicos do enunciado é dependente da noção de gêneros, pois sendo o enunciado-enunciação o elo na cadeia da comunicação verbal, os gêneros se constituem na engrenagem que movimenta o fluxo das relações dialógicas. Em Estética da criação verbal, nos ensaios O problema do texto e Os gêneros do discurso, respectivamente, Bakhtin (2000) se manifesta nos seguintes termos:

Problema das fronteiras do texto. O texto enquanto enunciado. Problema das funções do texto e dos gêneros do texto. Dois fatores determinam um texto e o tornam um enunciado: seu projeto (a intenção) e a execução desse projeto. Interrelação dinâmica desses dois fatores, a luta entre eles que imprime o caráter no texto. (BAKHTIN, 2000, p. 330). 
Ignorar a natureza do enunciado e as particularidades de gênero que assinalam a variedade do discurso em qualquer área do estudo linguístico leva ao formalismo e à abstração, desvirtua a historicidade do estudo, enfraquece o vínculo existente entre a língua e a vida. A língua penetra na vida através dos enunciados concretos que a realizam, e é também através dos enunciados concretos que a vida penetra na língua. $\mathrm{O}$ enunciado situa-se no cruzamento excepcionalmente de uma problemática. (BAKHTIN, 2000, p. 282).

A abordagem bakhtiniana tem implicações teóricas decisivas para uma teoria do conhecimento sobre a linguagem de fundo enunciativo-discursivo. O ponto de encontro entre enunciado e vida, ativado pelo gênero, é o que dá o tom à enunciação, uma vez que a entoação expressiva é proveniente de elementos que condicionam a interação discursiva, que está situada nos limites do verbal e do não verbal. Enunciação, discurso, texto, gêneros em seu estatuto de objetos empíricos não são constituídos à margem dos valores culturais, daí a importância de uma teoria que os tome na tessitura das práticas de linguagem. Os gêneros criam redes de sentido que se renovam ao longo do tempo e delineiam visões de mundo que seguem o fluxo de mudança da língua em uso, numa determinada cultura, num determinado tempo.

A concepção bakhtiniana de gênero como rede discursiva trouxe ganhos importantes para as formulações teóricas de campos dos estudos do texto e do discurso. Entender o gênero como um entrelaçamento de visões de mundo é entendê-lo como não limitado ao nível verbal ou exclusivamente linguístico e, sim, integrado ao todo da enunciação, a qual é constituída por atos verbais e atos do contexto cultural mais amplo, o que possibilita uma dada configuração textual. O texto está firmado numa produção cultural mediada pela linguagem. Nos estudos dialógicos, a noção de textualidade está de tal forma vinculada ao enunciado que se torna impossível não considerar texto e enunciação como uma única entidade. Assim deve ser compreendido o texto, como evento da interação social que inter-relaciona códigos verbais e culturais.

\section{Considerações finais}

Ao nos voltarmos para alguns dos objetos teóricos de perspectivas enunciativas e discursivas refletimos sobre diversificados aspectos da enunciação, o que trouxe para o centro do debate um objeto maior: a linguagem e seu sujeito, o homem que enuncia, descrevendo os lugares teóricos de onde se pensa sobre a linguagem e os lugares onde se movimenta a atividade linguageira.

No percurso da discussão empreendida, consideramos o lugar do texto em teorias enunciativas, algumas embrionárias, outras amplamente desenvolvidas, nas quais observamos o apego ao estruturalismo saussureano, o que, em grande medida, conservou o estudo do enunciado e da enunciação no plano verbal validando a língua como ordem própria.

Em contraponto, refletimos sobre a teoria dialógica da linguagem do coletivo pensante, formado por teóricos russos, nos atendo aos estudos de Volochínov e de Bakhtin, que tomam o enunciado como unidade-base da comunicação verbal para a organização dos constitutivos formais da língua, produtores dos discursos em situações de interação social determinadas por fronteiras históricoculturais. Nesse ponto, compreendemos o lugar de texto, discurso e gênero na teoria dialógica simbolizado nos elos estabelecidos entre formas textuais e formas discursivas mediadas pelo gênero. Desse modo, pudemos considerar o texto como representação do verbal e do não verbal, definindo-o como evento desenvolvido entre discursos e enunciados, em tempo e espaço próprios.

Ressaltamos que no pensamento dialógico o enunciar é determinado pelo lugar de onde se enuncia. Diante disso, o lugar do texto como foco da investigação sobre a linguagem é um caminho para o desvelamento do mundo verbal, “o texto [...] como dado primário de todas essas disciplinas, [...] e, de qualquer pensamento filosófico-humanista [...] onde não há texto, também não há objeto de estudo 
e de pensamento." (BAKHTIN, 2000, p. 329). Ainda que nos estudos bakhtinianos não se tenha uma teoria sistematizada sobre o texto, é ressaltada sua importância e seu papel como objeto de estudo, principalmente, nas ciências humanas, que o tem como objeto privilegiado de análise.

Diante das reflexões expostas, consideramos que o pensamento bakhtiniano, com sua produção teórico-filosófica, constitui-se como dispositivo analítico, uma vez que por meio do aparato teóricometodológico da teoria dialógica é possível que visualizemos a amplitude do papel da exterioridade na constituição dos textos, discursos, enunciados e gêneros, pois tais noções podem ser tomadas como as próprias categorias de análise da atividade linguageira. 


\section{Referências}

AUTHIER-REVUZ, J. Palavras incertas: as não coincidências do dizer. Campinas/SP: Unicamp, 1998.

BAKHTIN, M. Problemas da poética de Dostoievski. Paulo Bezerra (Trad.). 2. ed. Rio de Janeiro: Forense Universitária, 1997.

BAKHTIN, M. Estética da criação verbal. Maria Ermantina Galvão G. Pereira. (Trad.). 3 ed. São Paulo, Martins Fontes, 2000.

BAKHTIN, M. M.; VOLOCHINOV, V. N. Discurso na vida e discurso na arte (sobre poética sociológica). Carlos Alberto Faraco e Cristóvão Tezza (Trads.). mimeo, 1926/1976.

BALLY, Charles. Traité de stylistique française. Paris Klinecksieck, 1951.

BARROS, D.L.P. de. Contribuições de Bakhtin às teorias do discurso. In: Brait, B. (Org.). Bakhtin, dialogismo e construção do sentido. São Paulo, Editora da Unicamp, 2005, p. 25-36.

BENVENISTE, E. Problemas de lingüística geral I. Maria da Glória Novak e Maria Luisa Neri (Trads.). 5 ed. Campinas, SP: Pontes Editores, 2005.

BENVENISTE, E. Problemas de lingüística geral II. Eduardo Guimarães (Trad.). Campinas, SP: Pontes, 1989.

BEZERRA, Paulo. Posfácio: no limiar de várias ciências. In: BAKHTIN, Mikhail. In: Os gêneros do discurso. BEZERRA, Paulo (Trad.). São Paulo: Editora 34, 2016, p. 151-170.

BRAIT, Beth. Perspectiva dialógica. In: BRAIT, Beth; SOUZA-E-SILVA, Maria Cecília. (Orgs.). Texto ou discurso? São Paulo: Contexto, 2012, p. 9-29.

BRAIT, Beth. Análise e teoria do discurso. In: BRAIT, Beth (Org.). Bakhtin: outros conceitos-chave. São Paulo: Contexto, 2010, p. 9-31.

BRAIT, Beth. Uma perspectiva dialógica de teoria, método e análise. Gragoatá: Niterói, n. 20, p. 47-62, 1. sem. 2006. Disponível em <http://www.uff.br> Acesso em 20 dez. 2017.

BRAIT, Beth. Alguns pilares da arquitetura bakhtiniana. In: BRAIT, Beth (Org.). Bakhtin: conceitoschave. São Paulo: Contexto, 2005, p. 7-10.

BRAIT, Beth. O discurso sob o olhar de Bakhtin. In: GREGOLIN, Maria do Rosário; BARONAS, Roberto (Orgs.). Análise do Discurso: as materialidades do sentido. 2. ed. São Carlos: Editora Claraluz, 2003, p. 19-30.

BRANDIST, Craig. Repensando o Círculo de Bakhtin: novas perspectivas na história intelectual. CAMPOS, Maria Inês B.; SCHETTINI, Rosemary (Org.). São Paulo: Contexto, 2012.

CULIOLI, Antoine. Pour une linguistique de l'énonciation. Opérations et représentations, v. 1, 1990.

DUCROT, Oswald. O dizer e o dito. Pontes Editores, 1987

FARACO, Carlos Alberto. Linguagem \& diálogo: as idéias lingüísticas do círculo de Bakhtin. São Paulo: Parábola, 2009.

FARIA E SILVA, Adriana Pucci Penteado de. Bakhtin. In: OLIVEIRA, Luciano Amaral (Org.). Estudos do discurso: perspectivas teóricas. São Paulo: Parábola, 2013, p. 45-69.

FIORIN, José Luiz. Linguagem e interdisciplinaridade. Alea: Estudos Neolatinos, v. 10, n. 1, p. 29-53, 2008.

FIORIN, José Luiz. Introdução ao pensamento de Bakhtin. São Paulo: Ática, 2006.

FLORES, V. N.; TEIXEIRA, M. Introdução à linguística da enunciação. 2. ed., $1^{\mathrm{a}}$ reimpressão. São Paulo: Contexto, 2012. 
FLORES, V. N. et al. (orgs). Dicionário de linguística da enunciação. São Paulo: Contexto, 2009. FUCHS, Catherine. Paraphrase et énonciation. Editions Ophrys, 1994.

JAKOBSON, Roman. 1963. Essais de linguistique génerale. Paris, Editions de Minuit.

KERBRAT-ORECCHIONI, Catherine. L'énonciation de la subjectivité dans le langage. Armand Colin, Paris, 1980.

MAINGUENEAU, Dominique. Doze conceitos em análise do discurso. POSSENTI, Sírio e SOUZA-E-SILVA, Maria Cecília Perez de (Orgs.). São Paulo: Parábola, 2010.

MEDVIÉDEV, Iúri Pavlovitch; MEDVIÉDEVA, Dária Aleksándrovna. O círculo de M. M. Bakhtin: sobre a fundamentação de um fenômeno. Bakhtiniana. Revista de Estudos do Discurso. v. 9, p. 2646/Eng. 28-48, 2014.

PONZIO, Augusto. A revolução bakhtiniana: o pensamento de Bakhtin e a ideologia contemporânea. Valdemir Miotello (Trad.). 2. ed. São Paulo: Contexto, 2012.

POSSENTI, Sírio. Notas sobre língua, texto e discurso. In: BRAIT, Beth; SOUZA-E-SILVA, Maria Cecília. (Orgs). Texto ou discurso? São Paulo: Contexto, 2012.

SAUSSURE, Ferdinand de. Curso de linguística geral. Antônio Chelini, José Paulo Paes e Izidoro Blikstein (trad.). São Paulo: Cultrix, 1995.

SOBRAL, Adail. Texto, discurso, gênero: alguns elementos teóricos e práticos. Nonada Letras em Revista, v. 1, n. 15, p. 10-26, 2010. Disponível em <http://seer.uniritter.edu.br $>$ Acesso em 7 mai. 2017.

STELLA, Paulo Rogério. Palavra. In: BRAIT, Beth. Bakhtin: conceitos-chave. São Paulo: Contexto, 2005. p.177-190.

VOLOCHÍNOV, V. A construção da enunciação e outros ensaios. João Wanderley Geraldi (Trad.). São Carlos: Pedro \& João editores, 2013.

VOLOCHÍNOV,V. N. Marxismo e filosofia da linguagem. Michel Lahud e Yara Frateschi Vieira (Trad.). São Paulo: Hucitec, 1997.

VOLOSHINOV, Valentin Nikolaevich; BAKHTIN, M. M. Discurso na vida e discurso na arte. Sobre poética sociológica. Carlos Alberto Faraco e Cristovão Tezza (Trad.), para fins didáticos, 1976, p. 6-14.

TYLKOWSKI-AGEEVA, Inna. V. N. Vološhinov en contexte: essai d'épistémologie historique. Thèse présentée à la Faculté de lettres de l'Université de Lausanne pour obtenir le grade de docteur ès lettres. Lausanne, 2010. 